\title{
Association of lifestyle factors with menstrual problems and its treatment-seeking behavior among adolescent girls ${ }^{\text {is }}$
}

\author{
Shekhar Chauhan ${ }^{\mathrm{a}}$, Pradeep Kumar ${ }^{\mathrm{b}}$, Ratna Patel $^{\mathrm{c}}$, Shobhit Srivastava, RO ${ }^{\mathrm{b}, \mathrm{e}}$, \\ David Jean Simon ${ }^{\text {d, T. Muhammad }}{ }^{\text {a," }}$ \\ ${ }^{a}$ Department of Family and Generations, International Institute for Population Sciences, Mumbai, India \\ ${ }^{\mathrm{b}}$ Department of Survey Research \& Data Analytics, International Institute for Population Sciences, Mumbai, India \\ ${ }^{\mathrm{c}}$ Department of Public Health and Mortality Studies, International Institute for Population Sciences, Mumbai, India \\ ${ }^{\mathrm{d}}$ Paris 1 Pantheon Sorbonne University, Paris, France \\ ${ }^{\mathrm{e}}$ Research and Innovation, MAMTA Health Institute for Mother and Child, India
}

\section{A R T I C L E I N F O}

\section{Keywords:}

Menstrual problem

Adolescents

Treatment-seeking

Lifestyle factors

Heckprobit approach

\begin{abstract}
A B S T R A C T
Background: Lifestyle factors such as obesity, exercise, smoking, alcohol drinking, physical activity, and stress are related to menstrual problems among adolescents. Therefore, this study examines the association of lifestyle factors with menstrual problems among adolescent girls. Furthermore, the study also seeks to examine treatmentseeking behaviour for menstrual problems among adolescent girls.

Methods: Secondary data analysis was performed on cross-sectional survey data obtained from the Understanding the Lives of Adolescents and Young Adults (UDAYA) project survey. The sample size for this study was 12,707 adolescents girls aged 10-19 years. There are two outcome variables, i.e., menstrual problem and its treatmentseeking behaviour. The study employed the heckprobit selection model, which is a two-equation model.

Results: About $11 \%$ of adolescent girls suffered from menstrual problems, and among them, nearly one-third of adolescent girls sought treatment. The study noticed that menstrual problems were higher among adolescents who had severe depressive symptoms $[\beta: 0.53$; CI: $0.36,0.70]$, were using substance [ $\beta: 0.03 ; \mathrm{CI}:-0.24,0.29]$, and were not involved in physical activity [ $\beta$ : 0.06; CI: $-0.03,0.15]$. Adolescent girls from the richest wealth quintile were less likely to report menstrual problems [ $\beta$ : -0.15 ; CI: $-0.32,-0.04]$, however, were 0.45 times significantly more likely to seek treatment for menstrual problems [ $\beta$ : 0.45 ; CI: $0.12,0.78]$ than poorest adolescent girls.

Conclusions: There is a need to focus on improving health education on puberty and menstruation that may further improve the treatment-seeking for menstrual problems among adolescent girls, specifically in rural areas.
\end{abstract}

\section{Introduction}

Disorders in menses or its irregularities are a significant problem among adolescent girls. More than $75 \%$ of them experience some problems associated with menstruation. ${ }^{1}$ Changes in the normal menstrual patterns of adolescent girls may affect their physical and psychological well-being. ${ }^{2}$ Moreover, such disturbances have been well documented to have an impact on the physical and social activities of adolescents. $^{3}$ Simultaneously, it has been found that lifestyle factors such as obesity, exercise, smoking, alcohol drinking, physical activity, and stress are related to menstrual problems. ${ }^{4}$ In this context, worldwide research indicates that the prevalence of mental and emotional disorders and behavior in adolescents, especially girls, has been increased significantly in recent years, which may be due to the high level of limitations arising from gender roles. ${ }^{5}$ Besides, it is found that during the pubertal years, there are increases in depressive symptoms and anxiety. ${ }^{6}$ Previous studies have also shown that the onset of depression events is observed during adolescence and is associated with menstrual disorders. ${ }^{7}$

\footnotetext{
The manuscript has been read and approved by all the authors. Each author believes that the work in the manuscript represents honest work. This article is not simultaneously submitted to any other journal for review and/or publication and has not been published anywhere in full or in parts.

* Corresponding author.

E-mail addresses: shekhariips2486@gmail.com (S. Chauhan), pradeepiips@yahoo.com (P. Kumar), ratnapatelbhu@gmail.com (R. Patel), shobhitsrivastava889@ gmail.com (S. Srivastava), David.Jean-Simon@etu.univ-paris1.fr (D. Jean Simon), muhammad.iips@gmail.com (T. Muhammad).
} 
However, some cross-sectional and qualitative studies have found a reverse causal relationship between depressive symptoms and menstrual disorders among young women. ${ }^{8}$ Further, Earlier literature reported that smoking status and depressive symptoms are related to menstrual problems, and the impact of depressive symptoms on menstrual problems is more substantial in never smokers. ${ }^{9}$

Studies addressing the effect of smoking and alcohol consumption on female reproductive function provide conflicting results. ${ }^{10}$ Smoking-related behavior may disturb hormonal changes of the menstrual cycle. ${ }^{11}$ Moreover, daily physical activity helps maintain ideal body weight, with a rise in insulin sensitivity, and helps in the regularization of the menstrual cycle and overall feeling of well-being. ${ }^{12}$ The study also found that a low level of physical activity has the strongest association with irregular periods. Women who are both obese and sedentary have a higher prevalence of irregular periods than normal-weight women who exercise moderately. ${ }^{4}$ Further, body mass index (BMI) plays a vital role in maintaining menstrual cycle regularity. Studies have shown that obesity causes many menstrual problems such as anovulation, irregularity, and adverse pregnancy outcomes, with lasting effects for children. ${ }^{13}$

There is a growing body of literature suggesting that the changes in hormone levels associated with lifestyle factors result in various menstrual problems among young women. ${ }^{14}$ However, the examination of these factors with menstrual problems in adolescents in low-resource settings has received little attention. Furthermore, it has been noticed that previous studies of the relationship between lifestyle factors and menstrual problems among young and adult women involved age-related differences. On the other hand, with regard to treatment-seeking behavior, due to cultural norms, adolescent girls commonly hold negative attitudes and beliefs towards menstruation. ${ }^{15}$ This study involving adolescent girls aged $10-19$ years aimed to examine the association of lifestyle factors such as depressive symptoms, physical activity, and substance use with menstrual problems in adolescence and explore the treatment-seeking behaviour for menstrual disorders in adolescents. The study hypothesised that adverse lifestyle factors are positively associated with menstrual disorders during adolescence. It also hypothesised that adolescents with higher socioeconomic status are more likely to seek treatment for menstrual disorders.

\section{Methods}

\subsection{Data}

Secondary data analysis was performed on cross-sectional survey data from Understanding the Lives of Adolescents and Young Adults (UDAYA) project survey. The survey was conducted in two Indian states Uttar Pradesh and Bihar, in 2015-2016 by the Population Council under the Ministry of Health and Family Welfare, Government of India. The UDAYA collected detailed information on family, media, community environment, assets acquired in adolescence, and quality of transitions to young adulthood indicators. The sample size for Uttar Pradesh and Bihar was 10,350 and 10,350 adolescents aged 10-19 years, respectively. The required sample for each sub-group of adolescents was determined at 920 younger boys, 2,350 older boys, 630 younger girls, 3,750 older girls, and 2,700 married girls. The UDAYA adopted a multistage systematic sampling design to provide the estimates for states as a whole as well as urban and rural areas of the states. The detailed information on the sampling procedure and survey design was published elsewhere. ${ }^{16}$ The effective sample size for this study was 12,707 adolescents girls aged 10-19 years.

\subsection{Variable description}

\subsubsection{Outcome variable}

There are two outcome variables, i.e., menstrual problem and its treatment-seeking behavior. The first variable was formed using the question "Have you had menstrual problem in the last three months?" if the response was yes, then the second outcome variable was formed using the question "Did you seek treatment for this complaint?" Both the outcome variable was recoded in 0 "no" and 1 "yes."

\subsubsection{Explanatory variables}

1. Depressive symptoms were assessed by asking nine questions from the respondents; the respondent was asked about the symptoms for the past two weeks only. The questions included a. had trouble falling asleep or sleeping too much, b. feeling tired or having little energy, c. poor appetite or eating too much, d. trouble concentrating on things, e. had little interest or pleasure in doing things $\mathrm{f}$. feeling down, depressed or hopeless, g. feeling bad about yourself, h. been moving or speaking slowly, i. had thoughts that respondent would be better off dead. All the above questions were asked on a scale of four, i.e., 0 "not at all," 1 "less than one week," 2 "one week or more" and 3 "nearly every day." The scale of 27 points was then generated using egen command in STATA 14. (Cronbach alpha: 0.86 ). The variable was then recoded into three categories, i.e., a. Mild (0-9), b. Moderate (10-14) and c. Severe (15-27). Mild includes minimal and mild, moderate include moderate only and severe include moderately severe and severe. The categories were redefined for analytical purposes.

2. Substance use was recoded as "no" and "yes," i.e., respondents who either consume any type of substance, which include either tobacco or alcohol consumption or do not consume tobacco or alcohol.

3. Physical activity is categorized as "yes," i.e., engage in any physical activities and "no," which involve respondents who do not engage in any physical activities. Physical activities also include respondents who participated in any games or sports.

4. Body mass index (BMI) was calculated using BMI Z-scores. The WHO recommended cut-off points for overweight and obesity were BMI-for-age Z-score $>+1 \mathrm{SD}$ and $>+2 \mathrm{SD}$. The variable was recoded as thin $(<-2 \mathrm{SD})$, normal $(\geq-2 \mathrm{SD}$ and $\leq 1 \mathrm{SD})$ and overweight/obese $(>+1 \mathrm{SD})$.

5. Age was categorized into early adolescents (10-14 years) and late adolescents (15-19 years).

6. Education was recoded as no education, 1-7, 8-9, and 10 and above years of education.

7. Working status was coded as no "not working" and yes "working."

8. Media exposure was coded as no exposure, rare exposure, and frequent exposure.

9. The wealth index was recoded as poorest, poorer, middle, richer, and richest.

10. Caste was recoded as Scheduled Caste and Scheduled Tribe (SC/ ST) and non-SC/ST. The SC and ST are among the most disadvantaged socio-economic groups in India. The OBC is the group of people who were identified as "educationally, economically and socially backward". The OBC is considered low in the traditional caste hierarchy but somewhere above the boundary of the most disadvantaged groups. The "other" caste category is identified as having higher social status. ${ }^{17}$

11. Religion was recoded as Hindu and non-Hindu. The category of non-Hindu was recoded as so because the frequency of other religions was very low.

12. Residence was available in data as urban and rural.

13. Data was available for two states, i.e., Uttar Pradesh and Bihar. As the survey was conducted in these two states only.

\subsubsection{Statistical analysis}

Univariate and bivariate analysis was used to carve out the preliminary results. Chi-square test was conducted to find the significance level for the bivariate associations. Additionally, the study employed 
heckprobit selection model, which is a two-equation model. ${ }^{18}$ First, there is a selection model (in this study, referring to "Have you had menstrual problem in the last three months? (Yes or no)"). Secondly, there is an outcome model with a binary outcome (in this study refers to "Did you seek treatment for this complaint? (Yes or no)"). The model provides a two-step analysis and deals with the zero-sample issue, based on which it can accommodate the heterogeneity (i.e., shared unobserved factors) between respondents and then address the endogeneity (between occurrence menstrual problem and opting for its treatment) among adolescents.

\section{Results}

Fig. 1 displays the prevalence of menstrual problems among adolescent girl and their treatment-seeking behavior. About $11 \%$ of adolescent girls suffered from menstrual problems, and among them, nearly one-third of adolescent girls sought treatment.

The socio-demographic profile of the study population is presented in Table 1. It was found that seven per cent and ten per cent of adolescent girls had moderate and moderately severe/severe depressive symptoms, respectively. Only two per cent of adolescent girls were using substance use, one-third of adolescent girls were physically active, and nine per cent of girls were thin. The majority of respondents belonged to the late adolescent group, $36 \%$ of girls had $10 \&$ above years of education, and $18 \%$ of girls were working. About $53 \%$ of girls had frequent media exposure, and $16 \%$ of girls lived in urban areas.

Table 2 provides the prevalence of menstrual problems and their treatment-seeking behavior among adolescent girls by background characteristics. The menstrual problem was significantly higher among adolescent girls who had moderate depressive symptoms (15.6\%) than those who had minimal/mild ones (11.1\%). Though, it was least among those who had moderately severe/severe depressive symptoms. Moreover, adolescent girls who were using substance use (21.8\%) and physically active (11.7\%) reported more menstrual problems than their counterparts. Similarly, the menstrual problem was more prevalent among overweight/obese (16.1\%). However, the result was not significant. As expected, the prevalence of menstrual problems was higher among late adolescents (11.5\%); however, early adolescents sought more treatment than late adolescents (36.2\%). Adolescent girls with 10 $\&$ above years of education reported more menstrual problems $(11.8 \%)$ than adolescents with no education (11.3\%). Moreover, the prevalence of menstrual problems was higher among adolescent girls who had rarely $(11.5 \%)$ or frequently $(11.3 \%)$ media exposure than those with no media exposure. Media exposure among adolescent girls had a positive association with treatment-seeking behavior. Poorer girls reported significantly more menstrual problems (12\%); however, the richest girls sought more treatment (42.3\%). Likewise, the prevalence of menstrual

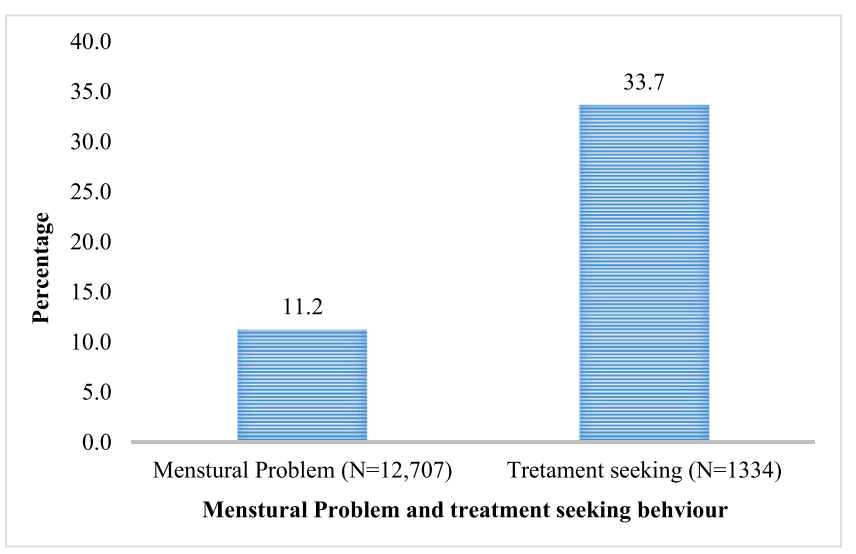

Fig. 1. Prevalence of menstrual problem among adolescent girls and their treatment seeking behavior.
Table-1

Socio-demographic profile of adolescents girls aged 10-19 years.

\begin{tabular}{|c|c|c|}
\hline Background variables & Sample & Percentage \\
\hline \multicolumn{3}{|l|}{ Depressive symptoms } \\
\hline Minimal/mild & 10,483 & 82.5 \\
\hline Moderate & 915 & 7.2 \\
\hline Moderately severe/severe & 1,309 & 10.3 \\
\hline \multicolumn{3}{|l|}{ Substance use } \\
\hline No & 12,399 & 97.6 \\
\hline Yes & 308 & 2.4 \\
\hline \multicolumn{3}{|l|}{ Physical activity } \\
\hline Yes & 4,242 & 33.4 \\
\hline No & 8,465 & 66.6 \\
\hline \multicolumn{3}{|l|}{ BMI Status } \\
\hline Thin & 299 & 9.1 \\
\hline Normal & 2,867 & 86.9 \\
\hline Overweight/obese & 132 & 4.0 \\
\hline \multicolumn{3}{|l|}{ Age (in years) } \\
\hline Early adolescents (10-14) & 580 & 4.6 \\
\hline Late adolescents (15-19) & 12,127 & 95.4 \\
\hline \multicolumn{3}{|l|}{ Education (in years) } \\
\hline No education & 1,650 & 13.0 \\
\hline $1-7$ & 2,783 & 21.9 \\
\hline $8-9$ & 3,754 & 29.5 \\
\hline 10 and above & 4,519 & 35.6 \\
\hline \multicolumn{3}{|l|}{ Working status } \\
\hline No & 10,427 & 82.1 \\
\hline Yes & 2,280 & 17.9 \\
\hline \multicolumn{3}{|l|}{ Media exposure } \\
\hline No exposure & 2,331 & 18.3 \\
\hline Rarely & 3,625 & 28.5 \\
\hline Frequently & 6,751 & 53.1 \\
\hline \multicolumn{3}{|l|}{ Wealth index } \\
\hline Poorest & 1,672 & 13.2 \\
\hline Poorer & 2,321 & 18.3 \\
\hline Middle & 2,773 & 21.8 \\
\hline Richer & 3,141 & 24.7 \\
\hline Richest & 2,800 & 22.0 \\
\hline \multicolumn{3}{|l|}{ Caste } \\
\hline $\mathrm{SC} / \mathrm{ST}$ & 3,252 & 25.6 \\
\hline Non-SC/ST & 9,455 & 74.4 \\
\hline \multicolumn{3}{|l|}{ Religion } \\
\hline Hindu & 9,975 & 78.5 \\
\hline Non-Hindu & 2,732 & 21.5 \\
\hline \multicolumn{3}{|l|}{ Residence } \\
\hline Urban & 2,055 & 16.2 \\
\hline Rural & 10,652 & 83.8 \\
\hline \multicolumn{3}{|l|}{ State } \\
\hline Uttar Pradesh & 8,626 & 67.9 \\
\hline Bihar & 4,081 & 32.1 \\
\hline
\end{tabular}

${ }^{a}$ Only selected adolescents who were eligible for BMI measurement; SC/ST: Scheduled Caste/Scheduled Tribe.

problems was significantly higher among SC/ST girls (11.8\%) than nonSC/ST counterparts. Though, the results were opposite for their treatment-seeking. Rural girls (11.7\%) reported significantly higher menstrual problems than urban ones. At the same time, urban girls (35.5\%) sought more treatment than their rural counterparts.

Estimates from the heckprobit model for menstrual problems and its treatment-seeking behavior among adolescent girls are presented in Table 3. Menstrual problem was 0.35 and 0.53 times significantly more likely among adolescent girls who had moderate [ $\beta$ : 0.35; CI: $0.21,0.48$ ] or moderately severe/severe [ $\beta$ : 0.53 ; CI: $0.36,0.70]$ depressive symptoms respectively than those had minimal/mild symptoms. Similarly, adolescent girls those were using substance [ $\beta$ : 0.03; CI: $-0.24,0.29]$ and were physically inactive $[\beta: 0.06$; CI: $-0.03,0.15]$ were 0.03 and 0.06 times more likely to report menstrual problem respectively compared to those who were not using substance use and physically active. Late adolescent girls were 0.27 times significantly more likely to report menstrual problems [ $\beta$ : 0.27 ; CI: $0.06,0.48]$ compared to early ones. However, late-adolescent girls were 0.19 times less likely to seek treatment for the menstrual problem [ $\beta$ : -0.19 ; CI: $-0.66,0.27]$ than their counterparts. The probability of menstrual problems to occur in 
Table 2

Bivariate analysis for menstrual problem and treatment seeking among adolescent girls (10-19 years).

\begin{tabular}{|c|c|c|c|c|}
\hline \multirow[t]{2}{*}{ Background variables } & \multicolumn{2}{|c|}{$\begin{array}{l}\text { Menstrual Problem }(\mathrm{N}= \\
12,707)\end{array}$} & \multicolumn{2}{|c|}{$\begin{array}{l}\text { Treatment seeking } \\
\text { (1334) }\end{array}$} \\
\hline & Percentage & $\mathrm{p}<0.05$ & Percentage & $\mathrm{p}<0.05$ \\
\hline Depressive symptoms & & * & & \\
\hline Minimal/mild & 11.1 & & & \\
\hline Moderate & 15.6 & & & \\
\hline Moderately severe/severe & 9.4 & & & \\
\hline Substance use & & * & & \\
\hline No & 16.8 & & & \\
\hline Yes & 21.8 & & & \\
\hline \multicolumn{5}{|l|}{ Physical activity } \\
\hline No & 10.3 & & & \\
\hline Yes & 11.7 & & & \\
\hline \multicolumn{5}{|l|}{ BMI Status $^{\mathrm{a}}$} \\
\hline Thin & 9.3 & & & \\
\hline Normal & 13.4 & & & \\
\hline Overweight/obese & 16.1 & & & \\
\hline Age (in years) & & $*$ & & \\
\hline Early adolescents (10-14) & 5.9 & & 36.2 & \\
\hline Late adolescents (15-19) & 11.5 & & 33.6 & \\
\hline \multicolumn{5}{|l|}{ Education (in years) } \\
\hline No education & 11.3 & & 34.4 & \\
\hline $1-7$ & 11.0 & & 33.8 & \\
\hline $8-9$ & 10.7 & & 36.5 & \\
\hline 10 and above & 11.8 & & 31.2 & \\
\hline \multicolumn{5}{|l|}{ Working status } \\
\hline No & 11.4 & & 34.1 & \\
\hline Yes & 10.4 & & 31.6 & \\
\hline Media exposure & & & & * \\
\hline No exposure & 10.7 & & 30.7 & \\
\hline Rarely & 11.5 & & 32.1 & \\
\hline Frequently & 11.3 & & 35.5 & \\
\hline Wealth index & & * & & $*$ \\
\hline Poorest & 11.6 & & 26.9 & \\
\hline Poorer & 12.0 & & 28.9 & \\
\hline Middle & 11.3 & & 34.6 & \\
\hline Richer & 11.6 & & 33.5 & \\
\hline Richest & 9.9 & & 42.3 & \\
\hline Caste & & $*$ & & $*$ \\
\hline $\mathrm{SC} / \mathrm{ST}$ & 11.8 & & 32.0 & \\
\hline Non-SC/ST & 11.0 & & 34.3 & \\
\hline Religion & & * & & $*$ \\
\hline Hindu & 11.0 & & 33.3 & \\
\hline Non-Hindu & 11.9 & & 35.0 & \\
\hline Residence & & * & & $*$ \\
\hline Urban & 8.6 & & 35.5 & \\
\hline Rural & 11.7 & & 33.4 & \\
\hline State & & * & & \\
\hline Uttar Pradesh & 11.5 & & 33.5 & \\
\hline Bihar & 10.6 & & 34.0 & \\
\hline
\end{tabular}

a Only selected adolescents where eligible for BMI measurement; SC/ST: Scheduled Caste/Scheduled Tribe; *if $\mathrm{p}<0.05$.

adolescent girls form the richest wealth quintile was low in comparison to adolescent girls from the poorest wealth quintile $[\beta:-0.15 ; \mathrm{CI}$ : $-0.32,-0.04]$. Adolescent girls from the richest wealth quintile were 0.45 times significantly more likely to seek treatment for menstrual problems [ $\beta$ : 0.45; CI: 0.12, 0.78]. Adolescent girls who lived in rural areas were 0.19 times significantly more likely to report menstrual problems [ $\beta$ : 0.19; CI: 0.09, 0.28] than urban areas. Moreover, rural girls were 0.06 times less likely to seek treatment for the menstrual problem [ $\beta:-0.06$; CI: $-0.27,0.15]$ compared to urban ones. However, the result was not significant.

\section{Discussion}

This article examined factors associated with menstrual problems among adolescent girls with an emphasis on lifestyle factors. Also, this study explored the treatment-seeking for menstrual problems among them. The study is important as previously available studies only
Table 3

Estimates from heck probit model for menstrual problems and its treatment seeking behavior among adolescent girls aged 10-19 years.

\begin{tabular}{|c|c|c|}
\hline \multirow[t]{2}{*}{ Background variables } & \multirow{2}{*}{$\begin{array}{l}\text { Outcome equation } \\
(12,707) \\
\text { Coef. }(95 \% \mathrm{CI})\end{array}$} & \multirow{2}{*}{$\begin{array}{l}\text { Selection Equation } \\
(1334) \\
\text { Coef. (95\% CI) }\end{array}$} \\
\hline & & \\
\hline \multicolumn{3}{|l|}{ Depressive symptoms } \\
\hline Minimal/mild & Ref. & \\
\hline Moderate & $0.35 *(0.21,0.48)$ & \\
\hline $\begin{array}{l}\text { Moderately severe/ } \\
\text { severe }\end{array}$ & $0.53 *(0.36,0.7)$ & \\
\hline \multicolumn{3}{|l|}{ Substance use } \\
\hline No & Ref. & \\
\hline Yes & $0.03(-0.24,0.29)$ & \\
\hline \multicolumn{3}{|l|}{ Physical activity } \\
\hline Yes & Ref. & \\
\hline No & $0.06(-0.03,0.15)$ & \\
\hline \multicolumn{3}{|l|}{ Age (in years) } \\
\hline $\begin{array}{l}\text { Early adolescents } \\
(10-14)\end{array}$ & Ref. & Ref. \\
\hline $\begin{array}{l}\text { Late adolescents } \\
(15-19)\end{array}$ & $0.27 *(0.06,0.48)$ & $-0.19(-0.66,0.27)$ \\
\hline \multicolumn{3}{|l|}{ Education (in years) } \\
\hline No education & Ref. & Ref. \\
\hline $1-7$ & $0.02(-0.14,0.17)$ & $-0.07(-0.37,0.23)$ \\
\hline $8-9$ & $-0.01(-0.15,0.13)$ & $0.01(-0.27,0.27)$ \\
\hline 10 and above & $0.06(-0.09,0.20)$ & $-0.20(-0.48,0.09)$ \\
\hline \multicolumn{3}{|l|}{ Working status } \\
\hline No & Ref. & Ref. \\
\hline Yes & $-0.09(-0.2,0.01)$ & $0.05(-0.17,0.27)$ \\
\hline \multicolumn{3}{|l|}{ Media exposure } \\
\hline No exposure & Ref. & Ref. \\
\hline Rarely & $0.03(-0.11,0.17)$ & $-0.03(-0.3,0.23)$ \\
\hline Frequently & $0.10(-0.03,0.23)$ & $-0.04(-0.29,0.21)$ \\
\hline \multicolumn{3}{|l|}{ Wealth index } \\
\hline Poorest & Ref. & Ref. \\
\hline Poorer & $-0.01(-0.16,0.13)$ & $0.04(-0.24,0.33)$ \\
\hline Middle & $-0.07(-0.22,0.09)$ & $0.19(-0.11,0.49)$ \\
\hline Richer & $-0.07(-0.22,0.08)$ & $0.18(-0.11,0.48)$ \\
\hline Richest & $-0.15^{*}(-0.32,-0.04)$ & $0.45 *(0.12,0.78)$ \\
\hline \multicolumn{3}{|l|}{ Caste } \\
\hline $\mathrm{SC} / \mathrm{ST}$ & Ref. & Ref. \\
\hline Non-SC/ST & $-0.03(-0.13,0.08)$ & $0.04(-0.17,0.25)$ \\
\hline \multicolumn{3}{|l|}{ Religion } \\
\hline Hindu & Ref. & Ref. \\
\hline Non-Hindu & $0.08(-0.03,0.2)$ & $-0.07(-0.3,0.15)$ \\
\hline \multicolumn{3}{|l|}{ Residence } \\
\hline Urban & Ref. & Ref. \\
\hline Rural & $0.19 *(0.09,0.28)$ & $-0.06(-0.27,0.15)$ \\
\hline \multicolumn{3}{|l|}{ State } \\
\hline Uttar Pradesh & Ref. & Ref. \\
\hline Bihar & $-0.06(-0.15,0.03)$ & $0.04(-0.13,0.21)$ \\
\hline /athrho & $-0.80 *(-1.34,-0.26)$ & \\
\hline rho & $-0.66 *(-0.87,-0.26)$ & \\
\hline Wald chi2 & 16.14 & \\
\hline Censored observation & 11,373 & \\
\hline Uncensored observation & 1,334 & \\
\hline Total observation & 12,707 & \\
\hline
\end{tabular}

SC/ST: Scheduled Caste/Scheduled Tribe; *if $\mathrm{p}<0.05$; Ref: Reference; Coef. Coefficient; BMI status not controlled due to low sample size.

examined prevalence and factors associated with menstrual problems and menstrual hygiene among adolescent girls, thus, ignoring the treatment-seeking for those menstrual problems. ${ }^{19}$ The study reported that around $11 \%$ of the adolescent girls suffered from menstrual problems. Previously available literature in different Indian settings has found a higher prevalence of menstrual problems among adolescent girls. ${ }^{20}$ Furthermore, results noted that only one-third (33.7\%) of the adolescent girls, who had a menstrual problem, took treatment for their menstrual problems. Treatment seeking for menstrual problems among adolescent girls is not discussed much in the Indian scenario; however, a study in urban Puducherry noted that around one-third (36\%) of the women seek treatment for their menstrual problems from a health facility. ${ }^{21}$ 
The results significantly noticed higher menstrual problems among adolescents who had severe depressive symptoms. Depression has been noticed as one of the important factors associated with menstrual problems. $^{22}$ However, the relation between depression and the menstrual problem may be bi-directional as the menstrual problem may also prompt depression among adolescents. ${ }^{23}$ Menstruating girls live in constant fear of menstruation signs (such as anxiety, depression, abdominal cramps, back pain, and tiredness) that may arise before a week from menstruation and may last after a week of menstruation. ${ }^{24}$

The study further noticed that substance use among adolescent girls might also increase the risk of menstrual problems; however, the results were not significant. Previously available literature unanimously agreed with the association between substance use and menstrual problems among adolescent girls. ${ }^{1}$ Substance use may promote depression among adolescents, which further may be linked to menstrual problems among them. ${ }^{9}$ Adolescents who do substance use consume nicotine during smoking, and nicotine may reduce the endometrial blood flow, which may further explain the association between smoking and menstrual problems. ${ }^{25}$ Results also noted that adolescents who were not involved in any physical activities were more likely to report menstrual problems; however, results were not statistically significant in the heck probit model. Previously available literature from various settings also confirmed the positive association between physical inactivity and menstrual problems among adolescent girls. ${ }^{26}$ Physical activity is believed to be associated with lower water retention and autonomic reactions in a girl's body that protect them from menstrual disorders; therefore, menstrual problems may be higher among those adolescents who are not involved in any physical activities. ${ }^{27}$

The study highlighted that late adolescents were more likely to report menstrual problems than early adolescents. Previously available literature also highlighted that menstrual problems increases with an increase in the gynaecological age among adolescent girls. ${ }^{28}$ Furthermore, treatment-seeking for menstrual problems was higher for early adolescents than late adolescents; however, results were not statistically significant. At the early ages of menstruation, adolescent girls tend to have poor knowledge about the menstrual cycle, and this could be attributed to their higher treatment seeking than late adolescents. Furthermore, as age increases, girls started seeking advice from their mothers and friends that may result in low treatment-seeking for menstrual problems among adolescent girls. ${ }^{29}$ Chan et al. believe that adolescent girls start accepting the menstrual problems as their family do not support them and taught them to avoid visiting doctors for such problems. $^{30}$

Results also noticed that adolescent girls from the richest wealth quintile were less likely to have menstrual problems and more likely to seek treatment for menstrual problems. Previously available studies are in line with our above finding. ${ }^{30}$ It is very much likely that an increase in wealth improves menstrual hygiene, ${ }^{31}$ which may further result in lowering the susceptibility to genital infections and therefore reducing menstrual problems. The study highlighted that menstrual problems were higher among rural girls; however, the treatment-seeking for menstrual problems was lower. Adolescent girls in rural areas have limited access to knowledge about menstrual hygiene, which may be attributed to their higher menstrual problems. ${ }^{32}$ Furthermore, girls in rural areas generally do not prefer to disclose their menstrual problems, which may be attributed to their lower treatment-seeking for menstrual problems. Also, limited health-care facilities in rural areas could hamper treatment-seeking among adolescent girls.

\section{Strengths and limitations of the study}

The data is cross-sectional in nature and therefore limits our understanding of possible causal inferences. Few study variables, such as substance use and physical activity, were self-reported and may not depict actual scenarios. Moreover, data is limited to only two states of India; therefore, study findings shall not be generalized to the country population. More research would be needed that shall extend upon the findings of this study. Despite the above limitations, the study has some strengths too. The study findings are based on large sample size. This study also explores various factors associated with treatment-seeking for menstrual problems among adolescent girls.

\section{Conclusion}

The prevalence of menstrual problems among adolescent girls is a serious concern; furthermore, suboptimal treatment-seeking for menstrual problems is another issue. The study noticed that menstrual problems were higher among adolescents who had depressive symptoms, using the substance, and were not involved in physical activity. Furthermore, menstrual problems were higher among late adolescents, adolescents from poor households, and from rural households. Overall, the treatment-seeking for menstrual problems was dismal among adolescents, specifically among adolescents from poor households. Treatment seeking for menstrual problems among adolescent girls should be explored as very limited girls were seeking treatment for menstrual problems. There is a need to focus on improving health education on puberty and menstruation that may further improve the treatmentseeking for menstrual problems among adolescent girls, specifically in rural areas. Adolescent girls feel threaten and embarrassed about being asked about the menstruation ${ }^{29}$; therefore, it is recommended to have a women-friendly health care system in place so that girls can seek treatment for their menstrual problems without any hesitation. Moreover, it is important to educate adolescent girls about various menstrual problems before they start menstruating so that they can enjoy a healthy menstrual life.

\section{Author's contribution}

Shekhar Chauhan: Writing-Original draft. Pradeep Kumar: Supervision, Conceptualization, Analysis, Methodology, Validation, Acquisition of data. Ratna Patel: Writing-review \& editing, Validation. Shobhit Srivastava: Conceptualization, Methodology, Supervision, software, validation, Acquisition of data. David Jean Simon: Writingreview \& editing. Muhammad T: Writing-Original draft, Writingreview \& editing, Validation.

\section{Funding}

The authors received no specific funding for this work.

\section{Declaration of competing interest}

The authors declare that they do not have conflict of interests.

\section{Acknowledgements}

This paper was written using data collected as part of Population Council's UDAYA study, which is funded by the Bill and Melinda Gates Foundation and the David and Lucile Packard Foundation. No additional funds were received for the preparation of the paper.

\section{References}

1 Lee LK, Chen PC, Lee KK, Kaur J. Menstruation among adolescent girls in Malaysia: a cross-sectional school survey. Singap Med J. 2006 Oct;47(10):869. https://www.sma. org.sg/smj/4710/4710a6.pdf.

2 Borjigen A, Huang C, Liu M, et al. Status and factors of menstrual knowledge, attitudes, behaviors and their correlation with psychological stress in adolescent girls. J Pediatr Adolesc Gynecol. 2019 Dec 1;32(6):584-589. https://doi.org/10.1016/ j.jpag.2019.08.007.

3 Azurah AG, Sanci L, Moore E, Grover S. The quality of life of adolescents with menstrual problems. J Pediatr Adolesc Gynecol. 2013 Apr 1;26(2):102-108. https:// doi.org/10.1016/j.jpag.2012.11.004. 
4 Akhila G, Shaik A, Kumar RD. Current factors affecting the menstrual cycle. Int $J$ Res Hosp Clin Pharm. 2020 Apr 3;2(1):18-21. https://doi.org/10.33974/ijrhcp.v2i1.165.

5 Van Droogenbroeck F, Spruyt B, Keppens G. Gender differences in mental health problems among adolescents and the role of social support: results from the Belgian health interview surveys 2008 and 2013. BMC Psychiatr. 2018 Dec 1;18(1):6. https:// doi.org/10.1186/s12888-018-1591-4.

6 Costello EJ, Mustillo S, Erkanli A, Keeler G, Angold A. Prevalence and development of psychiatric disorders in childhood and adolescence. Arch Gen Psychiatr. 2003 Aug 1;60(8):837-844. https://doi.org/10.1001/archpsyc.60.8.837.

7 Mohebi S, Parham M., Sharifirad G, Gharlipour Z. Social support and self - care behavior study. 1-6. https://doi.org/10.4103/jehp.jehp.

8 Titilayo A, Agunbiade OM, Banjo O, Lawani A. Menstrual discomfort and its influence on daily academic activities and psychosocial relationship among undergraduate female students in Nigeria. Tanzan J Health Res. 2009;11(4). https:// doi.org/10.4314/thrb.v11i4.50173.

9 Dorn LD, Negriff S, Huang B, et al. Menstrual symptoms in adolescent girls: association with smoking, depressive symptoms, and anxiety. J Adolesc Health. 2009 Mar 1;44(3):237-243. https://doi.org/10.1016/j.jadohealth.2008.07.018.

10 de Angelis C, Nardone A, Garifalos F, et al. Smoke, alcohol and drug addiction and female fertility. Reprod Biol Endocrinol. 2020 Dec;18(1):1-26. https://doi.org/ 10.1186/s12958-020-0567-7.

11 Allen SS, Bade T, Center B, Finstad D, Hatsukami D. Menstrual phase effects on smoking relapse. Addiction. 2008 May;103(5):809-821. https://doi.org/10.1111/ j.1360-0443.2008.02146.x.

12 Lakshmi SA. Impact of life style and dietary habits on menstrual cycle of college students. Int J Sci Res. 2015;4(4):2845-2847. Retrieved from https://www.ijsr.net/ archive/v4i4/SUB153744.pdf.

13 Yüksel M, Yüksel E. The effect of obesity on the menstrual period and hormonal parameters. Turkish J Health Sci Life. 2019;2(2):25-30. Retrieved from https:// dergipark.org.tr/en/pub/tihsl/issue/51521/553497.

14 Sakai H, Ohashi K. Association of menstrual phase with smoking behavior, mood and menstrual phase-associated symptoms among young Japanese women smokers. BMC Wom Health. 2013 Dec 1;13(1):10. https://doi.org/10.1186/1472-6874-13-10.

15 Siabani S, Charehjow H, Babakhani M. Knowledge, attitudes and practices (KAP) regarding menstruation among school girls in west of Iran: a population based crosssectional study. Int J Pediatr. 2018. https://doi.org/10.22038/ijp.2018.28633.2495.

16 Santhya KG, Acharya R, Pandey N, Gupta AK, Rampal S, Singh SK, Zavier AJ. Executive Summary: Understanding the Lives of Adolescents and Young Adults (UDAYA) in Uttar Pradesh, India (2015-16).

17 Srivastava S, Singh SK, Kumar M, Muhammad T. Distinguishing between household headship with and without power and its association with subjective well-being among older adults: an analytical cross-sectional study in India. BMC Geriatr. 2021; 21(1):1-12.

18 Heckman JJ. Sample selection bias as a specification error. Econometrica: J.Econom Soc. 1979:153-161.
19 Mathiyalagen P, Peramasamy B, Vasudevan K, Basu M, Cherian J, Sundar B. A descriptive cross-sectional study on menstrual hygiene and perceived reproductive morbidity among adolescent girls in a union territory, India. J Fam Med Prim Care. 2017 Apr;6(2):360. https://doi.org/10.4103/2249-4863.220031.

20 Kulshrestha S, Durrani AM. Prevalence of menstrual disorders and their association with physical activity in adolescent girls of aligarh city. Int J Health Sci Res. 2019;9 (8):384-393.

21 Laksham KB, Selvaraj R, Kar SS. Menstrual disorders and quality of life of women in an urban area of Puducherry: a community-based cross-sectional study. J Fam Med Prim Care. 2019 Jan;8(1):137. https://doi.org/10.4103/jfmpc.jfmpc_209_18.

22 Sahin N, Kasap B, Kirli U, Yeniceri N, Topal Y. Assessment of anxiety-depression levels and perceptions of quality of life in adolescents with dysmenorrhea. Reprod Health. 2018 Dec 1;15(1):13. https://doi.org/10.1186/s12978-018-0453-3.

23 Agarwal AK, Agarwal A. A study of dysmenorrhea during menstruation in adolescent girls. Indian J Community Med: Off Publ Indian Assoc.Prev. Soc. Med. 2010 Jan;35(1): 159. https://doi.org/10.4103/0970-0218.62586.

24 Mohamadirizi S, Kordi M. Association between menstruation signs and anxiety, depression, and stress in school girls in Mashhad in 2011-2012. Iran J Nurs Midwifery Res. 2013 Sep;18(5):402.

25 Parazzini F, Tozzi L, Mezzopane R, Luchini L, Marchini M, Fedele L. Cigarette smoking, alcohol consumption, and risk of primary dysmenorrhea. Epidemiology; 1994 Jul 1:469-472. https://www.jstor.org/stable/3702485.

26 Khalil SN, Alsaleem S, Siddiqui AF, Alshaikh AA, Althabet MM. Menstrual disorders and its effect on life activities of secondary school students in Abha, Saudi Arabia. htt ps://doi.org/10.21203/rs.3.rs-24247/v1; 2020.

27 Johnson WG, Carr-Nangle RE, Bergeron KC. Macronutrient intake, eating habits, and exercise as moderators of menstrual distress in healthy women. Psychosom Med. 1995 Jul 1;57(4):324-330.

28 Itagi C, Itagi S. Menstrual problems of late adolescents. Int J Pure Appl Biosci. 2017;5 (3):206-211. https://doi.org/10.18782/2320-7051.5015.

29 Chan SS, Yiu KW, Yuen PM, Sahota DS, Chung TK. Menstrual problems and healthseeking behaviour in Hong Kong Chinese girls. Hong Kong Med J. 2009 Feb;15(1): $18-23$.

30 Sharma S, Mehra D, Kohli C, Singh MM. Menstrual hygiene practices among adolescent girls in a resettlement colony of Delhi: a cross-sectional study. Int J Reprod Contracept Obstet Gynecol. 2017;6(5):1945-1951. https://doi.org/10.18203/23201770.ijrcog20171954.

31 Chauhan S, Kumar P, Marbaniang SP, Srivastava S, Patel R, Dhillon P. Examining the predictors of use of sanitary napkins among adolescent girls: a multi-level approach. PLoS One. 2021 Apr 30;16(4), e0250788. https://doi.org/10.1371/journal. pone. 0250788 .

32 Vyas S, Deepshikha D, Mahmood SE, Sharma P, Srivastava K, Shrotriya VP. Are menstrual knowledge outcome scores similar among rural and urban girls? J. Basic Clin Reprod Sci. 2017;6(1). https://doi.org/10.4103/2278-960X.194486. 